NBER WORKING PAPER SERIES

\title{
CONSUMER DISCRIMINATION AND SELF-EMPLOYMENT
}

\author{
George J. Borjas \\ Stephen G. Bronars
}

Working Paper No. 2627

\section{NATIONAL BUREAU OF ECONOMIC RESEARCH \\ 1050 Massachusetts Avenue \\ Cambridge, MA 02138 \\ June 1988}

This research is part of NBER's research program in Labor Studies. Any opinions expressed are those of the authors not those of the National Bureau of Economic Research. 
NBER Working Paper \#2627

June 1988

\section{CONSUMER DISCRIMINATION AND SELF-EMPLOYMENT}

\section{ABSTRACT}

Self-employment rates and incomes differ significantly by race. We show that these differentials arise in markets with consumer discrimination and Incomplete Information about the price of the good and the race of the seller. Equilibrium income distributions have two properties: mean black incomes are lower than mean white incomes, and the returns to ability are lower for black than for white sellers. Able blacks, therefore, are less likely to selfselect into the self-employment sector than able whites. Using the 1980 Census data, we find that observed differences in the self-employment income distributions are consistent with the theoretical predictions.

George J. Borjas Department of Economics Universicy of California Santa Barbara, CA 93106
Stephen G. Bronars

Department of Economics

University of California

Santa Barbara, CA 93106 


\section{Introduction}

After a long period of neglect, economists have recently begun to systematically analyze the role that self-employment plays in the labor market. This developing literature has already established a few interesting empirical regularities regarding the determinants of self. employment rates and the compensation of self-employed persons. For example, Blau (1987) finds that changes in tax laws and technology account for a large fraction of the observed increase in self-employment rates over the last two decades; Lazear and Moore (1984) document that the age/earnings profiles of self-employed persons are substantially flatter than the age/earnings profiles of salaried workers; and Evans and Leighton (1987) show that the transition rates into and out of self-employment are independent of age and labor market experience.

It is also well known (Moore 1983; Borfas 1986) that there exist sizable differences in the characteristics of the self-employment sector across ethnic/racial groups. In particular, whites have larger selfemployment rates and incomes than blacks or Hispanics. This fact is hard to interpret in the traditional framework of an employer discrimination model since self-employed persons have no reason to discriminate against themselves. ' This paper presents a theoretical and empirical analysis of the differences in both self-employment rates and incomes across racial groups. Our maintained hypothesis is that these differences are generated by consumer discrimination, whereby white consumers dislike purchasing goods and services from blacks and other minorities (Becker 1971).

The simplest consumer discrimination model assumes perfect information (i.e., consumers costlessly know the price of the good and the race of the sellers) and generates an equilibrium of complete segregation (Cain 1986). 
Racial differences in self-employment rates and incones in this model can only be created by differences across black and white consumers and/or sellers. In particular, black and white consumers have to differ in their preferences for goods or incomes, or there must be racial variation in endowments (of skills or wealth) of sellers. The theoretical analysis, therefore, then depends on a number of extraneous assumptions about heterogeneity between the black and white populations. 2

A more powerful analysis results if consumers can only obtain information about the price of the good and the race of the seller at a cost. The existence of imperfect information yields two important implications about the population income distributions of self-employed blacks and whites. First, the mean income level of blacks will be smaller than that of whites due to consumer discrimination. Second, the relative gains of entering the self-employment sector are reduced for able blacks. Intuitively, high ability self-employed blacks are more likely to expand the scale of their firm and cater to the larger white market. This expansion, however, requires that high ability blacks lower their prices in order to "compensate" white consumers for their disutility. Our empirical analysis uses the 1980 U.S. Census and shows that indeed blacks and other minorities are negatively selected into self-employment, but that whites are not. ${ }^{3}$

Section II presents a search model with consumer discrimination that generates equilibrium price and income distributions for white and black sellers. This model implies that skill wage differentials will be narrower in the self-employed sector for blacks than for whites. The empirical implications of the theory are tested in Section III. Our analysis documents a fundamental difference between whites and other racial groups in the self-selection mechanism that generates the pool of self-employed 
workers. Finally, Section IV sumarizes the results of the study.

\section{Theory}

A. Consumer Behavior

Suppose there are two types of sellers, black (b) and white (w), producing a homogeneous good. The fraction of black sellers in the population is $\theta$, where $\theta$ is assumed to be less than one-half throughout the analysis. There are also black and white buyers, and, for simplicity, we assume that the fraction of black buyers in the population is also given by $\theta .{ }^{4}$ Finally, we assume that all consumers maximize utility, are riskneutral, have a zero discount rate, and an infinite time horizon.

In order to focus on the essential aspects of consumer discrimination, we assume that white consumers have a taste for discrimination against black sellers, but that black buyers are indifferent about the race of the seller. ${ }^{5}$ This implies that if black sellers charge price $P$, a white buyer will percelve the price as being $P /(1-d)$, where $d$ is the discrimination coefficient. Define $R$ to be the consumer's valuation of the good. The maximum price white consumers are willing to pay for a unit of the good purchased from a black seller is $R(1-d)$. White consumers who purchase from white sellers, and black consumers who purchase from any seller, are willing to pay up to $R$ for the good. We assume that consumer demand is inelastic below the price $R$.

Consumers randomly contact sellers. Imperfect information implies that consumers do not know (without incurring some search costs) the price of the good and the race of the seller. If the buyer rejects the seller's "price/race quote", the cost of contacting another seller is C dollars. The optimal search strategy has a constant reservation price property where 
reservation prices differ according to both the race of the seller and the race of the buyer.

Let $V(P, i, j)$ denote the value of a price offer $P$ from a seller of race $i$ to a consumer of race $j(i, j=b, w)$. This value function is defined by:

$$
V(P, i, j)=\max (R-D(i, j) P, 0,-C+E V(P, i, j))
$$

where $D(i, j)=1 /(1-d)$ for $i=b, j-w$, and $D(i, j)-1$ otherwise. Expectations are taken over the distribution of offer prices $F(P)$.

A reservation price $P *(i, j)$ is implicitly defined by:

$$
R \cdot D(i, j) P *(i, j)=\max (0,-C+E V(P, i, j))
$$

The reservation price $P \star(i, j)$ is the price offer from a seller of race $i$ to a buyer of race $j$ that leaves the buyer indifferent between purchasing the good at that price and continuing to search. Since there are four types of consumer/seller matches that can occur in this model, there are four possible reservation prices $[P \star(w, w), P \star(w, b), P \star(b, w), P \star(b, b)]$ for consumers. We denote the reservation price distribution by $G(P \star)$. Equation (2) implies that $G(P \star)$ depends on $F(P)$.

\section{B. Seller Behavior}

Sellers are assumed to be utility maximizers, with a utility function given by $U=I-H^{\delta} / \delta$, where $I$ is self-employment Income, $H$ is hours worked, and $\delta>1$. Sellers engage in two kinds of activities. First, goods are produced at rate $\beta$ per unit of time, where $\beta$ differs across sellers due to ability. Second, there is a period of time during which sellers and 
consumers conduct the transaction. Suppose that all sellers, regardless of their ability, can complete $\alpha$ transactions per unit of time. During this "contact" period between sellers and consumers, sellers are prevented from producing the good. Gi' in that consumers randomly encounter sellers, information regarding the price of the good and the race of the seller is also exchanged during this contact period. Incomplete information implies that some contacts between consumers and sellers will not result in a sale and the time costs incurred during the contact period cannot be recovered. Thus incomplete information imposes an opportunity cost on sellers.

Let $r$ be the fraction of contacts that result in a sale. Sellers offer a price/race quote that leads to one of three possible selling strategies: sell to all consumers $(r-1)$; (b) sell only to blacks $(r-\theta)$; and (c) sell only to whites $(r-1-\theta)$. Let $s$ be the fraction of the workday spent in production. Efficiency requires that $s \beta H-\alpha r(1-s) H$, hence $s-\alpha r /(\alpha r+\beta){ }^{6}$

The price charged by the seller, $P(r)$, is a function of the segregation behavior chosen: $P(r)$ must be less than or equal to the reservation prices of all the consumers it chooses to serve. The objective of the seller, therefore, is to choose $\mathrm{H}$ and, so as to maximize:

$$
U-\frac{\alpha r \beta}{\alpha r+\beta} P(r) H-H^{\delta} / \delta
$$

The maximization of ( 3 ) is easier to conduct in two stages. First, consider the seller's optimization over H. For a given price, $P(r)$, the seller's indirect utility function is given by:

$$
U *-(1 / c)\left[\frac{\alpha+\beta}{\alpha \tau+\beta} P(r)\right]^{\varepsilon}-y / c
$$


where $\varepsilon=\delta /(\delta \cdot 1)$, and $y$ is the income level associated with utilitymaximizing behavior. The second stage of the maximization process involves the choice of segregation behavior by the seller. The indirect utility function in (4) can be evaluated at the three alternative values of, , and a seller chooses the value of $r$ that maximizes utility. The functional form in (3) implies that utility-maximization leads to the same segregation behavior as income-maximization. "This is easily verified since $U *(r)>U *\left(r^{\prime}\right)$ if and only if $y(r)>y\left(\tau^{\prime}\right)$, for $r r^{\prime}$.

As noted earlier, sellers differ in their ability to produce output (as measured by the parameter $\beta$ ). For simplicity, we assume that there are two types of sellers (within each race group). High ability sellers are indexed by the productivity parameter $\beta_{\mathrm{h}}$, low ability sellers are indexed by $\beta_{\ell}\left(\beta_{\mathrm{h}}>\right.$ $\beta_{\ell}$ ), and the fraction of high ability sellers in the population is $\pi$. We assume the same ability distribution for both race groups so that any income differentials in the model cannot be attributed to skill differences.

The four types of sellers in the market generate the offer price distribution $F(P)$ over the prices $P_{w h}, P_{w \ell}, P_{b h}$, and $P_{b \ell}$, where offer prices are indexed over the race and ability of the seller. Since sellers can charge no more than the minimum reservation price of all the consumers it chooses to serve, $F(P)$ will depend on $G(P *)$, the distribution of reservation prices of consumers.

\section{Equilibrium Price and Income Distributions}

Because of imperfect information, the offer price distribution is likely to be non-degenerate. We, therefore, must characterize the properties of the equilibrium price distribution in the market (as in Reinganum 1979; and Carlson and McAfee 1983), before analyzing income differentials across 
sellers. We use a Nash equilibrium concept so that in equilibrium no seller has an incentive to alter his offer price, and no buyer has an incentive to alter his reservation price, taking the actions of other agents as given. We define an equilibriurs price distribution as a set of offer prices and segregation strategies for sellers, and reservation prices for consumers, such that given $F(P)$ consumers choose optimal reservation prices $P \star(i, j)$ that collectively generate $G\left(P^{\star}\right)$; and given $G\left(P^{\star}\right)$ sellers choose utility maximizing price, output, and segregation strategies that collectively generate $F(P)$.

Several important properties of an equilibrium price distribution follow from our assumptions about preferences and technology and the definition of an equilibrium:

1. The price sellers charge is the minimum of the reservation prices of the consumers they choose to serve. Sellers will be unable to sell to all the consumers they wish to serve if they charge a price higher than the minimum reservation price; and, given inelastic demand, sellers have no incentive to reduce the price below the minimum reservation price.

ii. Reservation prices are ordered as follows:

$$
P \star(w, w) \geq P \star(w, b)-P \star(b, b) \geq P \star(b, w)-(1-d) P \star(w, w)
$$

The (maximum) price whites are willing to pay white sellers [P* $(w, w)]$ is at least as great as the price blacks are willing to pay white sellers $[P \star(w, b)]:$ White buyers set higher reservation prices if they contact a white seller because their potential gains from search are reduced by the possibility of encountering a black seller in their next contact. Further, since blacks are indifferent to the seller's race, blacks have a single 
reservation price $[P \star(w, b)=P \star(b, b)]$. Third, the price blacks are willing to pay a black seller $\left[p^{\star}(b, b)\right]$ is at least as high as the price whites are willing to pay a black seller $[P \star(b, w)] .^{8}$ Finally, our definition of consumer discrimination implies that $P \star(b, w)=(1-d) P *(w, w)$.

iii. If sellers serve a segregated market it will be of the same racial group as the seller. Equation (5) indicates that sellers of race $i$ must charge the same or lower price in order to attract buyers of race $j(i+j)$. Sellers of race $i$, therefore, have no incentive to cater solely to buyers of race $j$.

iv. High ability sellers of any race group only segregate if low ability sellers of that race group have also segregated. This result is implied by the production technology since the opportunity costs of "wasted contacts" (i.e., contacts that do not result in a sale) are greater the more able the seller. This behavior implies that the offer price distribution can be ordered as follows:

$$
P_{w \ell} \geq P_{w h} \geq P_{b l} \geq P_{b h}
$$

This ranking follows from the fact that the lowest price a white seller will ever charge is the black reservation price, and this is the highest price that a black seller can ever charge. Further, since within each race group high ability sellers are more likely to integrate, they cannot charge a higher price than low ability sellers if they want to cater to all consumers.

In order to assess the impact of consumer discrimination on economic welfare, it is essential to compare the income distributions of black and white sellers. Equation (4) shows that income levels will depend on the offer price distribution. It is impossible to derive a single equilibrium 
price distribution for all ranges of parameter values $\left(\alpha, \beta_{\ell}, \beta_{h}, \theta, d\right.$, and C). Nevertheless, the model allows us to characterize the first two moments of the equilibrium income distributions regardless of the specific price distribution observed $i$. the market. Equation (4) implies that the utilitymaximizing level of income for a seller of race $i$ and ability level $k$ ( $k=h$, 2) is:

$$
y_{i k}=\left[\frac{\alpha r_{i k} \beta_{k}}{\alpha r_{i k}+\beta_{k}} P\left(\tau_{i k}\right)\right]^{\varepsilon}
$$

where $r_{1 k}$ is the segregation strategy chosen by the seller, and $P\left(r_{i k}\right)=P_{i k}$ is the price associated with that segregation strategy.

It is easy to show that the mean income of black sellers is lower than the mean income of white sellers. A white seller of ability $k$ an always opt to charge the price $P_{b k}$ and retain at least as many contacts as a black seller of ability k. Moreover, equation (6) shows that even if black sellers are retaining all contacts, white sellers can, in general, charge a higher price and also retain all contacts. Therefore, white sellers can always do better than black sellers.

Consumer discrimination also affects the variances of the population income distributions. The variance of $\log$ incomes for race group $i\left(\sigma_{i}^{2}\right)$ is given by $\pi(1-\pi)\left(y_{1 h} / y_{i \ell}\right)^{2}$, where $\pi$ is the fraction of sellers that are high ability. Note that since the variance of $\log$ incomes depends on the ratio of high-to low-ability incomes, higher variances are associated with higher returns to ability for that race group. The white/black ratio of standard deviations in $\log$ incomes is then given by $\Delta=\left(y_{w h} / y_{w l}\right)+\left(y_{b h} / y_{b l}\right)$. It can be shown that, under certain conditions, consumer discrimination leads to the result $\Delta>1$, so that white sellers have a higher return to ability than 


\section{black sellers.}

Define $\gamma_{w}$ as the ratio of the high ability white seller's income to the income he would have received had he chosen the same segregation strategy as a low ability white seller; and $\gamma_{b}$ as the ratio of the low ability black seller's income to the income he would have recelved had he chosen the same segregation strategy as a high ability black seller. ${ }^{9}$ By construction, the "selection biases" $\gamma_{w}$ and $\gamma_{b}$ are greater than or equal to one, since each seller selected the segregation strategy that maximized indirect utility. Furthermore, $\gamma_{w}$ and $\gamma_{b}$ are strictly greater than unity if low ability workers choose a different segregation strategy than high ability workers within each race group. The ratio $\Delta$ can be written as:

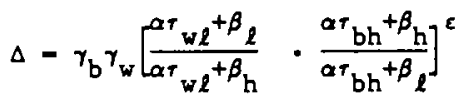

The discussion above and inspection of ( 8 ) leads to the following result.

PROPOSITION: The equilibrium income distributions of black and white selfemployed workers have the following properties.

i. Mean white income exceeds mean blask income.

11. If low ability whites retain more contacts than high ability blacks $\left(r_{w \ell}>r_{b h}\right)$, the white income distribution has more variance than the black income distribution. If low ability whites retain as many contacts as high ability blacks $\left({ }^{+} \ell^{-r} b h\right)$, the white income distribution has more variance than the black income distribution if, for at least one race group, there are differences in the segregation behavior of high and low ability sellers (i.e., either $\gamma_{b}$ or $\gamma_{w}$ exceeds unity). 
iii. If low ability whites retain fewer contacts than high ability blacks $\left(r_{w 2}<r_{b h}\right)$, the ratio of standard deviations $\Delta$ is bounded from below by:

$$
\Delta>\gamma_{b} \gamma_{w}(1-\theta)^{c}
$$

$$
\begin{aligned}
& \text { where } \gamma_{b} \gamma_{w} \geq 1 \text { with a strict inequality if, for at least one race } \\
& \text { group, there are differences in the segregation behavior of high and } \\
& \text { low ability sellers. }
\end{aligned}
$$

These results are quite intuitive. Suppose, for instance, that both low ability whites and high ability blacks integrate. Consumer discrimination reduces the relative incomes of high ability blacks because they must charge a lower price in order to retain white customers. If high ability blacks segregate they must discard more contacts than white sellers regardless of the segregation strategy of whites. The opportunity cost of segregation is clearly highest for high ability blacks, and hence the black income distribution is compressed relative to the white income distribution.

Suppose, on the other hand, that ${ }^{r_{w}}<{ }^{<}{ } b h$. This implies that high ability blacks integrate, but low ability whites segregate. High ability blacks must lower prices in order to retain white consumers. Low ability whites could have integrated (and charged a higher price than high abilicy blacks), but chose not to because their incomes are raised by segregating. In effect, this reduces white income inequality, and thus the impact of consumer discrimination on the ratio of variances cannot be determined. The lower bound in equation (9), however, implies that as long as blacks are a small minority it is unlikely that the black income distribution has less 
variance than the white income distribution.

Our result that the returns to ability are lower for black sellers than for white sellers has important implications for the sorting of individuals between self-employment and other sectors of the labor market. ${ }^{10}$ In particular, able blacks have less incentive to be self-employed than able whites. Consumer discrimination and incomplete information, therefore, have an impact not only on the relative size of the black self-employment sector, but also on the composition of sellers in that sector. ${ }^{11}$ Moreover, this prediction of the impact of consumer discrimination does not follow from a simpler complete information model.

Zero search costs imply that buyers and sellers are sorted perfectly by race and that a single price will prevail in the market. Since consumers can costlessly identify the price of the good and the race of the seller in all firms, there are no "wasted contacts". Equation (7) implies that the income of a seller of race 1 and ability $k$ is given by:

$$
y_{i k}-\left[\frac{\alpha \beta_{k}}{\alpha+\beta_{k}} p\right]^{\varepsilon}
$$

where $P$ is the market price. Using equation (10), it is easy to verify that the ratio of standard deviations of white to black incomes, $\Delta$, is unity. Consumer discrimination in a complete information model, therefore, does not lead to racial differences in the returns to ability. 12

\section{Employer Discrimination}

Our analysis of consumer discrimination in the self-employment sector shows that the population income distribution for blacks will be more compressed than the population income distribution for whites. These 
population incose distributions are the ones that would be observed if every person in the labor market became self-employed. The choice of selfemployment, however, is endogenous and is based on a comparison of income opportunities in the seif-employed and salaried sectors. The actual composition of persons in the self-employed pool, therefore, will also depend on the characteristics of the salaried income distribution. Hence it is necessary to determine whether employer discrimination in salaried jobs leads to the same types of income compression as consumer discrimination in selfemployed jobs. 13

Suppose that within each race group there are two types of workers, highand low-ability, with wage rates $r_{i h}$ and $r_{i l}(i-b, w)$, and that labor can be measured in efficiency units, $\beta$, such that $\beta_{h}>\beta_{\ell} \cdot{ }^{14}$ Competition in the labor market requires that for each racial group the price of an efficiency unit of labor $(r / \beta)$ be the same for all skill groups. This implies that $r_{i h} / r_{i \ell}-\beta_{h} / \beta_{\ell}(i-b, w)$. It follows immediately that the black/white wage ratio is independent of skill level. Labor market competition, therefore, ensures that employer discrimination does not lead to any compression or widening of skill differentials within each race group. 15

It has been argued that affirmative action raises the demand for black skilled workers relative to other blacks (Leonard, 1984). There is, however, litcle economic reason for this to occur. Suppose, for example, that a law mandates that $\theta$ percent blacks be hired at the same wage as whites. A profitmaximizing firm will meet this requirement by hiring the cheapest possible black labor available, namely low-skilled black workers. This result follows from the fact that affirmative action programs are specified in terms of the relative number of blacks hired, and not in terms of efficiency units. Hence the simplest model of employer discrimination suggests that, if anything, 
there may be an increase in the relative demand of unskilled black workers.

In summary, consumer discrimination reduces the returns to ability for blacks (relative to whites) in the self-employment sector. Employer discrimination (in the absence of affirmative action) does not change the relative returns to ability for blacks in the salaried sector. These theoretical implications, therefore, suggest that the skill composition of self-employed and salaried workers will differ by race. In particular, skilled blacks have more incentives to enter the salaried sector than skilled whites, and unskilled blacks have more incentives to enter self. employment than unskilled whites. Therefore, blacks are more likely than whites to be negatively selected into self-employment and positively selected into salaried jobs.

\section{Empirical Analysis}

\section{A: Framework}

Individuals compare income streams between the salaried sector, $w_{0}$, and the self-employment sector, $w_{1} \cdot{ }^{16}$ These income streams depend on a vector of observed demographic variables, $X$ :

$$
\begin{aligned}
& \ln w_{0}-X \beta_{0}+\varepsilon_{0} \\
& \ln w_{1}-X \beta_{1}+\varepsilon_{1}
\end{aligned}
$$

where the random variables $\varepsilon_{0}$ and $\varepsilon_{1}$ are joincly nomally distributed, have mean zero, variances $\sigma_{0}^{2}$ and $\sigma_{1}^{2}$, and correlation coefficient $\rho_{01}$. The unobserved characteristics, $\varepsilon$, correspond to the efficiency differences $\beta$ in the theoretical model above.

For simplicity, we assume that all individuals start their careers in the 
salaried sector, and that transition to the self-employment sector involves a cost. These mobility costs are proxied by a vector of observable variables. Define $C$ to be the ratio of these mobility costs to $w_{0}$. Then:

$$
c-\mathrm{X}_{c} \beta_{c}+\varepsilon_{c}
$$

The disturbance ${ }^{c} c$ is also assumed to be normal, with mean zero, variance $\sigma_{c}^{2}, \operatorname{Corr}\left(\varepsilon_{0}, \varepsilon_{c}\right)-\rho_{O c}$, and $\operatorname{Corr}\left(\varepsilon_{1}, \varepsilon_{c}\right)-\rho_{1 c}$.

The self-employment decision 1 s determined by the sign of the index function:

$$
I-\ln \left[\frac{w_{1}}{w_{0}(1+C)}\right] \approx x\left(\beta_{1}-\beta_{0}\right)-x_{c} \beta_{c}+v-2 \pi+v
$$

where $v-\varepsilon_{1}-\varepsilon_{0}-\varepsilon_{c}$. The vector $z$ contains all the variables in $x$ and $x_{c}$, and the coefficient vector $\pi$ gives the reduced form impact of the demographic variables on the propensity to become self-employed.

The composition of the samples in the self-employed and salaried sectors can be determined by considering:

$$
\begin{aligned}
& E\left(\ln w_{0} \mid X, I<0\right)-X \beta_{0}+\frac{\sigma_{0} \sigma_{1}}{\sigma_{\mathrm{v}}}\left[\left(\rho_{01}-\frac{\sigma_{0}}{\sigma_{1}}\right)-\rho_{0 \mathrm{c}} \frac{\sigma_{\mathrm{c}}}{\sigma_{1}}\right] \lambda_{0} \\
& E\left(\ln w_{1} \mid \mathrm{X}, \mathrm{I}>0\right)-\mathrm{X} \beta_{1}+\frac{\sigma_{0} \sigma_{1}}{\sigma_{\mathrm{v}}}\left[\left(\frac{\sigma_{1}}{\sigma_{0}}-\rho_{01}\right)-\rho_{1 \mathrm{c}} \frac{\sigma_{\mathrm{c}}}{\sigma_{0}}\right] \lambda_{1}
\end{aligned}
$$

where $\lambda_{0}--\phi(z) / \Phi(z) ; \lambda_{1}-\phi(z) /(1-\Phi(z)) ; z--2 \pi / \sigma_{v} ; \phi$ is the density function of the standard normal, and $\$$ is the distribution function of the 
standard normal.

The implications of the model are best understood in the special case where $\rho_{O C}=\rho_{1 c}=0$. As long as $\rho_{01}$ is positive (i.e., able persons do well in both self-employed and salaried jobs), positive selection into selfemployment occurs if $\sigma_{1} / \sigma_{0}>\rho_{01}$, and negative selection occurs otherwise. Therefore, when the income distribution is compressed in the self-employment sector relative to the salaried sector, it is likely that the most able persons stay in the salaried sector, and that low ability persons (in terms of e) become self-employed.

In the more general case where the costs of entering the self-employment sector and earnings are correlated, the coefficients of the selection variable in (15) and (16) also depend on the correlation coefficients $\rho_{0 \mathrm{c}}$ and $\rho_{l c}$, and on the variance $\sigma_{c}^{2}$. Though little is known about these parameters, negative selection into self-employment is still more likely among blacks than among whites as long as the black income distribution in the selfemployment sector has less variance than the white income distribution.

\section{B. Data}

The empirical analysis uses individual data from the $1 / 100$ B Sample of the 1980 U.S. Census of Population. In order to focus on self-employment in the non-agricultural sector, our data consist of observations of white, black, Asian, and Hispanic men (aged 25-64), residing in metropolitan areas, who are not employed in the agricultural industry. The data include all observations in the $1 / 100$ random sample for individuals who are minority and self-employed, and randon samples for other groups. ${ }^{17}$ We use the census definition of a self-employed person as one whose main fob is in that sector. There are other ways of defining self-employwent, and our use of 
alternative definitions of self-employment did not lead to different results. Finally, the Income measure used throughout the study is the logarithm of weekly income in 1979.

Table 1 presents sumary statistics for these data, and shows that selfemployment rates differ substantially across racial and ethnic groups. White males are nearly three times as likely as black males to be selfemployed. Hispanic men are also much less likely to be self-employed than whites, while Asians have self-employment rates that are nearly identical to whites. Mean self-employment incomes, like salaried incomes, display considerable variation across groups. For instance, blacks earn about 38 percent less than whites in the salaried sector, and about 47 percent less than whites in the self-employment sector. Hispanics earn about 38 percent less than whites in the salaried sector, and about 28 percent less in the self-employment sector. Thus, among blacks and Hispanics, the income gap between minorities and whites in self-employment incomes is nearly as large (if not larger) than the gap in the salaried sector.

Table 2 presents the means of some demographic variables for selfemployed and salaried workers. Self-employed persons are significantly more likely to be college educated than salaried persons. For instance, 38 percent of self-employed whites are college educated, but only 29 percent of salaried whites are. Even among blacks, 19 percent of self-employed persons are college educated, while only 12 percent of salaried blacks are. Table 2 also indicates a large age differential between workers in the two sectors: Self-employed workers are about 3 to 5 years older than salaried workers. Finally, self-employed workers are more likely. to be married with a spouse present in the household than salaried workers. Among whites, for example, 81 percent of self-employed persons are married, spouse present, but only 75 
percent of salaried persons are. Among blacks, the respective statistics are 68 and 61 percent.

\section{Results}

Table 3 presents the probit regressions on the determinants of the selfemployment probability for each of the groups. These regressions estimate the parameters of the reduced form index function in equation (14). Like the descriptive statistics in Table 2, the regressions indicate that more educated and older persons are more likely to be self-employed. In addition, higher education levels for the wife increase the probability of self-employment. In general, the qualitative effects of these explanatory variables are essentially the same for all the groups.

The probit regressions in Table 3 also include measures of the ethnic/racial composition of the labor market's population. These variables are defined by the fraction of the SMSA's population that is black, Hispanic, or Asian. In general, these "enclave" variables have a weak impact on self-employment propensities. The only "own" effect that is even marginally significant is the positive impact of percent black on the black self-employment rate. The regressions also include a number of other local labor market characteristics (e.g., the crime rate, population growth, etc.). These variables proxy for labor market specific differences in the costs of becoming self-employed. In general, the coefficients of these variables differ in terms of statistical significance as well as sign across the ethnic/racial groups. To conserve space, therefore, the coefficients of these additional local labor market variables are not presented in Table 3 .

The white probit regression can be used to predict what the average self-employment rate of the various minority groups would be if the same 
mechanism that determined self-employment rates for whites generated minority self-employment rates. This predicted probability is presented in the last row of Table 3 and is calculated using: ${ }^{18}$

$$
\hat{P}-\sum_{i} \Phi\left(Z_{1} \hat{n}_{w}\right) / N
$$

where $z_{i}$ is the vector of variables (for individual 1 ) included in the probit; $\hat{\pi}_{w}$ is the vector of probit coefficients estimated in the white sample; and $\mathrm{N}$ is the sample size. The sumation in (17) is conducted over all persons in the particular ethnic/raclal group.

The predicted probabilities show that the self-employment rates of blacks and Hispanics would be almost identical to those of whites if the minority groups faced the same structure determining self-employment, while the self-employment rate of Asians would exceed that of whites. For example, the average black has a predicted self-employment rate of 10.5 percent (as compared to the actual 4.5 percent self-employment rate); and the average Hispanic has a predicted rate of 12.0 percent (as compared to the actual 7.0 percent self-employment rate). Both blacks and Hispanics, therefore, would have self-employment rates remarkably close to the 11.8 percent self-employment rate of whites if the groups faced the same structure. This implies that differences in characteristics across groups cannot explain the large variation in observed self-employment rates. Instead, the observed variation in self-employment rates is due to differences in the mechanism that selects the self-employment pool in each of the race/ethnic groups.

The probit regressions in Table 3 are used to estimate selectivity corrected earnings functions in each of the two sectors for each of the 
groups. 19 The earnings regressions are presented in Table 4 for the selfemployed sector, and in Table 5 for the salaried sector. Before turning to the selectivity variables, it is instructive to briefly analyze the impact of the demographic variables on incomes in each sector. One striking result is that the impact of the demographic variables is basically the same for self-employment and salaried incomes for all race groups. There are, of course, differences in the magnitudes of the coefficients by race and by sector, but the overall comparisons of the earnings equations do not support the hypothesis that earnings determination in the two sectors is qualitatively different. 20

of course, the main focus of the study is the determination of the kinds of selections that generate the pools of self-employed and salaried workers. The type of selection is determined by the sign of the coefficients of the selectivity variables. One key result in Table 4 is that the coefficient of the selectivity variable in the self-employment income regression is positive for whites, but zero or negative for all minority groups. Since, as defined in equation (16), the selectivity variable in the self-employment sector $\left(\lambda_{1}\right)$ is positive, this result implies that there is positive selection into self-employment in the white sample, negative selection into self-employment among Hispanics and Asians, and zero selection into selfemployment among blacks.

The same dramatic differences in the selectivity coefficients are observed in the regressions estimated in the salaried sample (Table 5). In particular, this coefficient is positive for whites but negative and significant for all minority groups. Since the selectivity variable $\left(\lambda_{0}\right)$ is negative in the salaried sector, the coefficients imply that there is negative selection in the composition of the salaried sample for whites, but 
that there is positive selection generating the salaried samples of minorities.

Among whites, therefore, we observe that the most able persons enter selfemployment, and that the least skilled persons remain in the salaried sector. Among the various minority groups, however, essentially the opposice result is observed: the most able persons remain in the salaried sector, and the least skilled become self-employed. It is important to note that this empirical result is exactly what is predicted by our theoretical model. In particular, the existence of consumer discrimination reduces the gains from self-employment for the most able members of a minority group.

Remarkably, these findings persist even when the self-employment and salaried sectors are stratified into two major occupation groups: professionals and others. ${ }^{21}$ Table 6 presents the coefficients of the selectivity variables in each of the two sectors by occupation group. White self-employed persons are positively selected regardless of occupation, while minority self-employed workers are never positively selected, and are often negatively selected. Conversely, white salaried persons are not positively selected, while minority salaried persons are always positively selected.

Our theoretical model is based on the premise that personal contacts between consumers and sellers are essential for the presence of consumer discrimination. To the extent that the degree of personal contact differs by occupation group, It seems reasonable to expect that the intensity of selection would differ by occupation. However, it is unclear a priori which occupation group has more contact with their consumers: Do accountants and lawyers have more personal contact with their clients than salesmen and plumbers? Moreover, disaggregating the sample into two broadly defined 
occupations may not be sufficient to capture the subtle variations in selection that arise as the degree of personal contact varies. Unfortunately, any further disaggregation leads to increasingly smaller samples and to less robust estimation of the parameters.

The selectivity results presented in this section arise because the variance in self-employment incomes (relative to the variance in salaried incomes) is reduced for minorities due to consumer discrimination. This implication of the model can be tested directly by calculating the standard deviation of the population income distributions in each of the two sectors. Table 7 presents estimates of the standard deviations of $\log$ incomes in the two sectors by race. The predicted population standard deviation (i.e., the variation that would arise if all individuals entered the sector after controlling for differences in demographic variables) is calculated using the formula suggested by Heckman (1980, p. 217). Table 7 also presents the (square root of the) truncated mean square error from the selectivitycorrected OLS earnings regressions.

A key prediction of our model is that there will be less income inequality among self-employed minorities than among self-employed whites Table 7 indicates that the population standard deviations of self-employment income are indeed lower among blacks and Hispanics than among whites. Selection, however, is determined by the ratio of population standard deviations between the seif-employment and the salaried sectors. The results in Table 7 reveal that the ratio of the standard deviation of selfemployment incomes to salaried incomes is always greater for whites than for minority groups (particularly blacks and Hispanics). For example, the predicted population standard deviation ratio for whites is 2.4 , but only 1.3 for blacks and Hispanics. 
These ratios differ by race, in part, because in the salaried sector the minority income distributions exhibit more dispersion than the white income distribution. We do not know why this result arises since there has been litcle study of racial differences in the second moment of wage distributions. ${ }^{22}$ Nevertheless, it is important to note that this result is not simply generated by the algebra underlying the construction of the population standard deviation because it is also found in the simpler MSEbased measure of income inequality (which is based on the residuals of the OLS regression).

The results in Table 7, therefore, are consistent with the selection patterns indicated by the earnings functions in Tables 4 and 5 . Although the measures of income inequality in Table 7 are generated from the same earnings functions as the selectivity coefficients, the sorting patterns observed in the data are not derived from our estimates of the population variances. There is nothing in the statistical procedure that forces the patern of selectivity coefficients and population variances to be consistent with each other.

Finally, we use the earnings functions in Tables 4 and 5 to decompose the observed wage differential between whites and the various minority groups in each of the two sectors. This decomposition, presented in Table 8, is conducted by setting the selectivity variables $\left(\lambda_{0}, \lambda_{1}\right)$ equal to zero so that, in effect, we are comparing means of population income distributions. The results for blacks and Hispanics reveal that even after controlling for differences in demographic characteristics the income gap between minorities and whites remains. Self-employed blacks, for example, have 19 percent lower mean incomes than whites. This result is consistent with the implication of our theoretical model. The theoretical prediction that self-employed 
minorities have lower Incomes than whites, however, is not confirmed by the analysis of the Asian data, since in this case Asians actually earn more than whites, on average.

\section{Summary}

This paper presents a theoretical and empirical analysis of racial differences in self-employment propensities and incomes. The theoretical model is based on the hypothesis that white consumers dislike purchasing goods from self-employed minority workers, and that it is costly to acquire information about the price offers and racial characteristics of sellers. Our equilibrium search model not only implies the existence of price dispersion in the marketplace, but also yields two interesting predictions. First, minority self-employed workers have lower incomes than white selfemployed workers. Second, the income distribution of self-employed minority workers has less variance than the income distribution of self-employed whites. The latter result implies that the gains to self-employment for able minorities are relatively smaller than the gains to self-employment for able whites. Therefore, able minorities have much lower incentives to become self-employed and minorities are more likely than whites to be negatively selected into self-employment.

The empirical analysis used the 1980 U.S. Census and showed large differences in both self-employment rates and incomes across the ethnic/racial groups. The self-employment rates of blacks and Hispanics, for example, were found to be at least 50 percent lower than those of whites, and the earnings differential between self-employed whites and blacks (or Hispanics) was almost as large (if not larger than) the racial wage 
differential in the salaried sector. In addition, our analysis revealed that minorfties are negatively selected into self-employment while whites exhibit positive selection. Conversely, whites are negatively selected into salaried jobs, while the most able minorities remain in the salaried sector. The theory of consumer discrimination, therefore, provides unique insights into the composition of the pool of workers who self-select between the two employment sectors. 


\section{REFERENCES}

Becker, Gary S. The Economics of Discrimination. 2d ed. Chicago: University of Chicago, 1971.

Blau, David M. "A Time-Series Analysis of Self-Employment in the United States." Journal of Political Economy 95 (June 1987): 445-67. . "Self-Employment and Self-Selection in Developing Country Labor Markets." Southern Economic Journal 52 (October 1985): 351-63. Borjas, George J. "The Self-Employment Experience of Immigrants." Journal of Human Resources 21 (Fall 1986): 485-506.

Cain, Glen G. "The Economic Analysis of Labor Market Discrimination: A Survey." In Handbook of Labor Economics, edited by Orley $C$. Ashenfelter and Richard Layard. Amsterdam: North Holland, 1986.

Carlson, John A. and McAfee, R. Preston. "Discrete Equilibrium Price Dispersion." Journal of Political Economy 91 (June 1983): 480-93.

Evans, David S. and Leighton, Linda S. "Self-Employment and Earnings Over the Life Cycle." Mimeographed. New York: Fordham University, 1987.

Goldberg, Matchew S. "Discrimination, Nepotism, and Long-Run Wage Differentials." Quarterly Journal of Economics 96 (May 1982): $307-19$. Heckman, James J. "Sample Selection Bias as a Specification Error." In Female Labor Supply, edited by James P. Smith. Princeton: Princeton University Press, 1980.

Lazear, Edward P. and Moore, Robert L. "Incentives, Productivity, and Labor Contracts." Quarterly Journal of Economics 99 (May 1984): $275-95$.

Leonard, Jonathan S. "Employment and Occupational Advance under Affirmative Action." Review of Economics and Statistics 66 (August 1984): 377-85. Maddala, G.S. Limited Dependent and Qualitative Variables in Econometrics. 
New York: Cambridge University Press, 1983.

Moore, Robert L. "Employer Discrimination: Evidence from Self-Employed Workers." Review of Economics and Statistics 65 (August 1983): 496-501.

Reinganum, Jennifer F. "A Simple Model of Equilibrium Price Dispersion," Journal of Political Economy 87 (August 1979): $851-58$.

Roy, Andrew D. "Some Thoughts on the Distributions of Earnings." Oxford Economic Papers 3 (June 1951): $135-46$.

Scitovszy, Tibor. "A Note on Profit Maximisation and Its Implications." Review of Economfc Studies 11 (1943-1944): 57-60.

U.S. Bureau of the Census. State and Metropolitan Area Book, 1986.

Washington: Government Printing Office, 1986.

Welch, Finis and Smith, James P. "Inequality: Race Differences in the Distribution of Earnings." International Economic Review 20 (June 1979): $515-26$ 


\section{FOOTNOTES}

We are grateful to Steve Trejo, to seminar participants at the Labor Summer Workshop of the National Bureau of Economic Research and the University of Chicago, and to a referee for helpful comments. The research was supported by a grant from the Economic Development Administration, U.S. Department of Commerce, and by a grant from the National Science Foundation (Grant No. SES-8604973).

${ }^{1}$ In fact, if employers are the only source of racial discrimination in the marketplace, one would expect that self-employment rates for minorities would be higher since these groups would find it less profitable to be in salaried jobs.

2 For example, if we assume that white and black consumers are "perfect substitutes" in the marketplace (i.e., they have equal incomes and identical preferences) the black self-employment sector would be a mirror image of the white self-employment sector, though on a smaller scale.

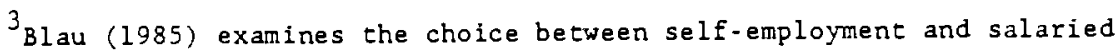
jobs in a self-selection model where individuals differ in their managerial ability. His model, however, does not generate predictions about the types of selection that are expected to arise.

4 The assumption that the percent black among consumers equals the percent black among sellers is not necessary for the theoretical analysis. It only simplifies the notation and the presentation.

5 The model can be generalized by allowing black buyers to discriminate against white sellers. This extension complicates the presentation of the analysis, without fundamentally changing the nature of the results. This generalization will be discussed in more detail below. 
${ }^{6}$ Invoking the Law of Large Numbers, we assume that sellers making $n$

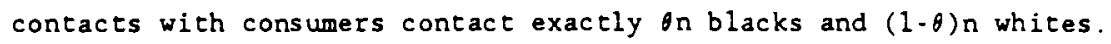

Allowing the number of consumers of each race group to be a random variable to the firm does not alter the important results of our model, but simply generates variation in income and output across firms of the same race and ability level. In addition, we focus on a "steady state" equilibrium of the model, where the number of consumers leaving the market in each period just equals the number of new consumers entering the market. For simplicity, we also assume that each consumer who is searching makes exactly one contact in the period.

${ }^{7}$ This property follows from the assumption that utility is additively separable in income and leisure (Scitovsky 1943).

${ }^{8}$ Note that the ordering in equation (5) implies that there can be at most three prices in the equilibrium distribution. The fact that black and white sellers may charge the same price implies that price alone is not a perfect signal for the race of the seller.

${ }^{9}$ The precise definitions of $\gamma_{w}$ and $\gamma_{b}$ are given by:

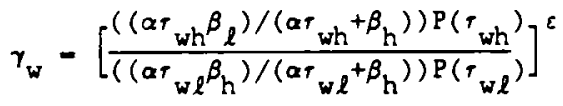

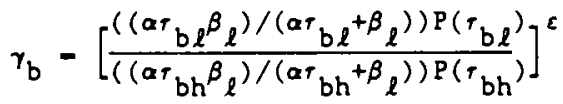

${ }^{10}$ Although the proposition has been derived under the assumption that contacts are random, and that each seller's probability of encountering a consumer of race $f$ equals the population proportion of consumers of race $j$, 
we can generalize our results to allow for racial "ghettos". The existence of racial ghettos implies that although contacts between buyers and sellers are random, sellers encounter a larger fraction of consumers of their same race than the overall population proportions. It is easy to show that the proposition still holds given the alternative values of $\tau$ which result from racial ghettos, although "ghettoization" does increase the incentives for both whites and blacks to segregate.

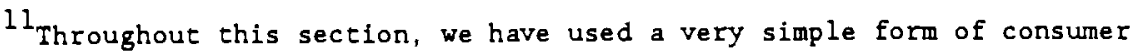
discrimination by ignoring the possibility that black consumers prefer to purchase from black sellers. It can be shown that the key result that the black income distribution (under certain conditions) is more compressed than the white income distribution holds even in the general case where both types of consumers have a taste for discrimination. The ranking of black and white mean incomes, however, depends on the relative strengths of discrimination by the two types of consumers and on the percent black in the marketplace.

12 The discussion implicitly assumes that white and black buyers are "perfect substitutes" in terms of their demands for the good. Suppose instead that black buyers have less income and therefore a lower demand for the good. High ability black sellers may not be able to attain their optimal level of output by catering to only blacks, and will have to lower their price to $P(1-d)$ in order to attract white buyers. Competition among black sellers reduces the price in all black firms to $P(1 \cdot d)$. This leads to lower black self-employment incomes, but it is easy to show that $\Delta$, the ratio of standard deviations of white and black incomes, is still unity.

${ }^{13}$ See Goldberg (1981) for a modern treatment of the Becker model of employer discrimination.

${ }^{14}$ By efficiency units we mean that one unit of high ability labor is a 
perfect substitute for $\beta_{h} / \beta_{l}$ units of low ability labor.

${ }^{15}$ An extension of Reinganum's (1979) search model to the case of employer discrimination under incomplete information reveals that, under some conditions, wage skill differentials remain independent of race. The returns to ability for blacks, however, may be reduced in more general formulations of the model that allow for differential search costs by ability level.

${ }^{16}$ The self-selection model presented in this section is due to Roy (1951).

${ }^{17}$ Our sample consists of 3.38 of white salaried workers; 338 of white self-employed workers, and black and Hispanic salaried workers; all Asian salaried workers, and all black, Hispanic, and Asian self-employed workers in the 1980 Census data. Due to the stratified sampling technique, the probit regressions reported below are weighted (and their standard errors corrected) to reflect the sample composition. Finally, in order to match the individual data with SMSA-specific characteristics we restrict the sample to persons residing in the 75 largest SMSAs. The source of these SMSA-specific and local labor market variables is the U.S. Bureau of the Census (1986).

${ }^{18}$ This formula ensures that the predicted probability in the white sample is identical to the observed self-employment rate of whites. See Maddala (1983, p. 26).

${ }^{19}$ The aggregate labor market characteristics listed in the notes to Table 3, which proxy for mobility costs, are omitted from the earnings functions.

${ }^{20}$ Tables 4 and 5 can also be used to assess the impact of "enclave" effects on earnings. The comparison of the relevant coefficients across the two sets of regressions, however, does not provide any evidence that enclave effects have à differential impact on self-employment and salaried incomes. 
${ }^{21}$ The professtonal category includes all persons working in managerial and professional specialty occupations according to the 1980 Census occupation codes. All other workers are in the residual category which includes sales, service, craftsmen, operators, and laborers. The fraction of salaried workers who are in the professional occupation group is 31.28 for whites, 14.28 for blacks, 14.0 for Hispanics, and 34.38 for Asians. The fraction of self-employed workers who are in the professional occupation group is 46.7 for whites, 29.68 for blacks, 34.1 for Hispanics, and 52.48 for Asians.

${ }^{22} \mathrm{Smith}$ and Welch (1979) present an analysis of income inequality by race, and also find that the black income distribution in the salaried sector exhibits substantially more dispersion than the white income distribution. 
TABLE 1

Summary Statistics

$\begin{array}{lccc}\text { Group } & \begin{array}{r}\text { Self-Employment } \\ \text { Probability }\end{array} & \begin{array}{r}\text { Self-Employment } \\ \text { Sector }\end{array} & \begin{array}{r}\text { Salaried } \\ \text { Sector }\end{array} \\ \text { Whites } & .118 & 5.842 & 5.849 \\ \text { Blacks } & .045 & 5.371 & 5.466 \\ \text { Hispanics } & .070 & 5.558 & 5.465 \\ \text { Asians } & .119 & 5.792 & 5.646\end{array}$




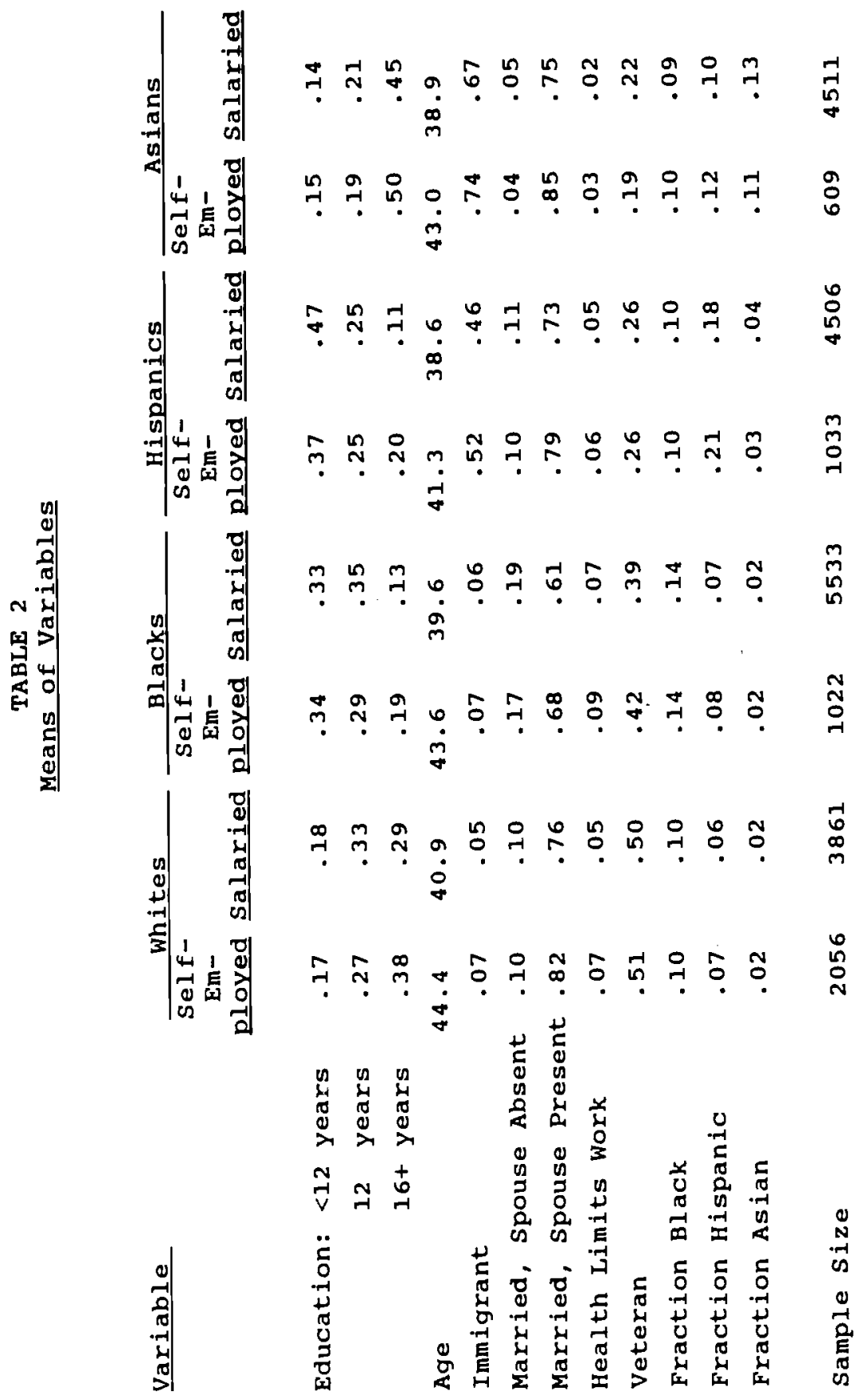



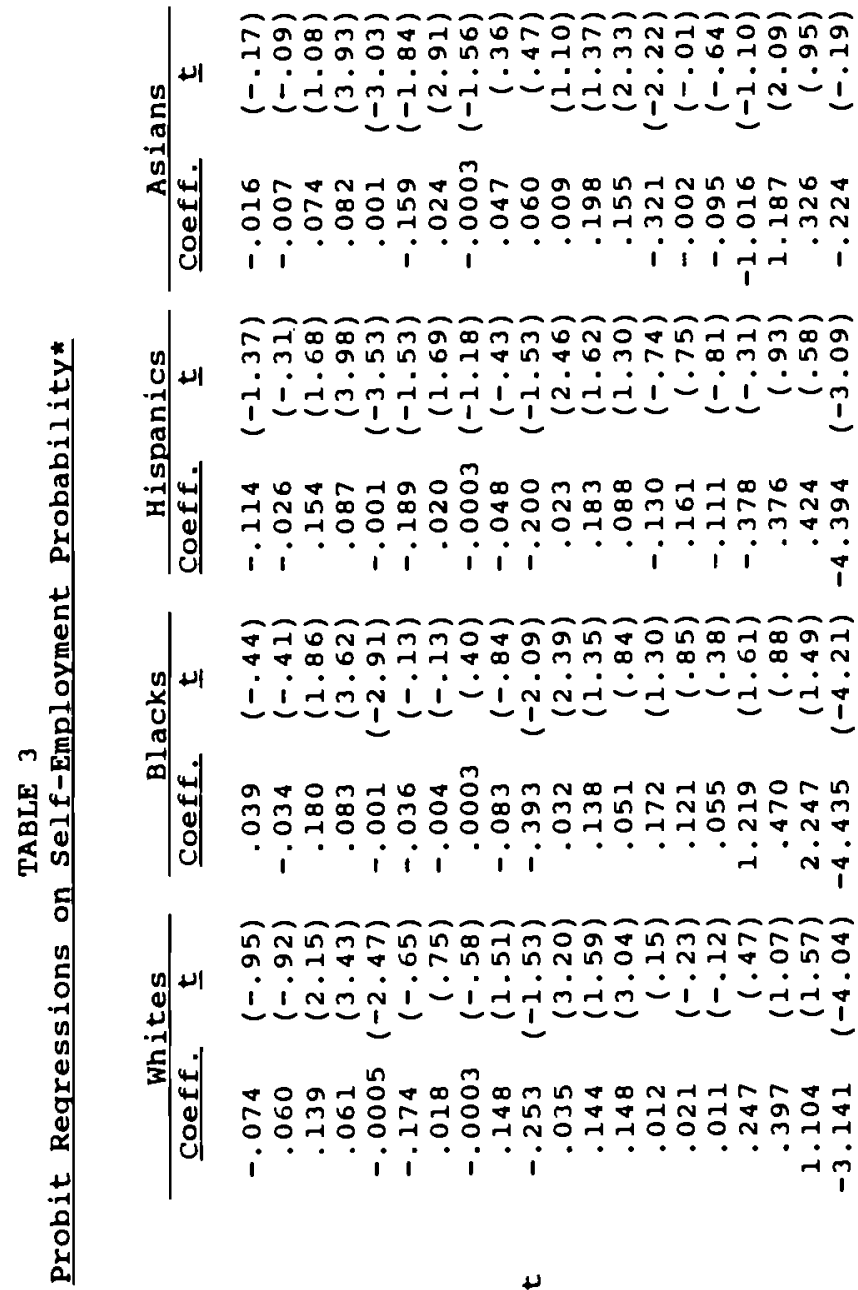

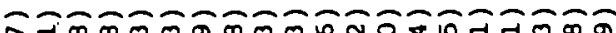
$m m b a$ in ? ? ? ? ? ! ? ? ? ! ?

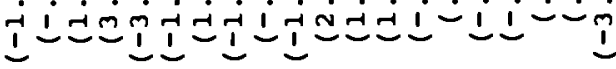

* สn न O $i$ i i i i i i

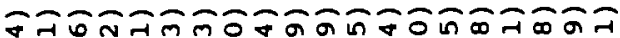
$\forall+\infty \omega r+\infty \circ m m \infty m m \omega \infty \sim N$ u

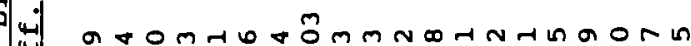

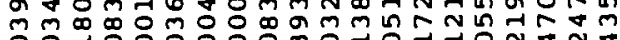

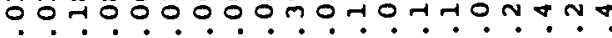

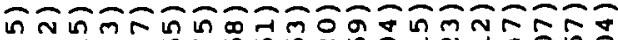

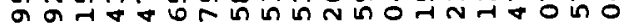
un $\quad$ i

3) 잉

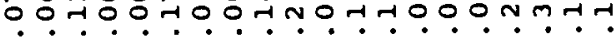

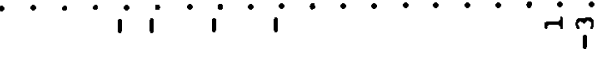

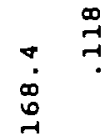

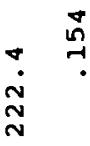

$\begin{array}{ll} & 0 \\ \text { m } & \text { I } \\ m & \end{array}$

菖

5 in

$+1+1$

4 니도

10 30

$3 \cdot-1$ u

웅도

D. 80

ง $\stackrel{0}{x} \dot{0}$ 选过 $\mu=\frac{5}{8}$

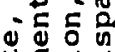

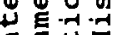

TEW

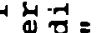

$\stackrel{0}{\circ}=$ 워 ब $=$ 네 긍듀.

등 :

㤩尔它

54

ด $\rightarrow$ है

ज

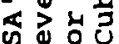

$\begin{array}{ll} & n \\ \infty & 0 \\ \infty & 0\end{array}$

运

क व

논

- $8 x$

400

$0+12$

ด 4 \& 4

온 운

כ

in. 5 in

(1) 4 .

U 0

E $0 \frac{n}{\pi}$

ช土

0 넌

이 0

$\rightarrow 0$

유응

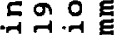

- ه

ज记

办

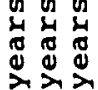

$\nabla \underset{0}{0} \frac{1}{0}$

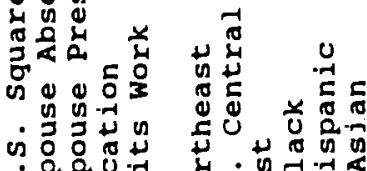

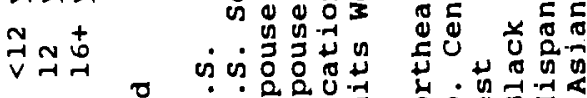

융ำ

是命 엉

그을

(5)

号守

¿ 5

6ิ 0 -

(1) 0 on

(1) 0

넌 도

E 040 


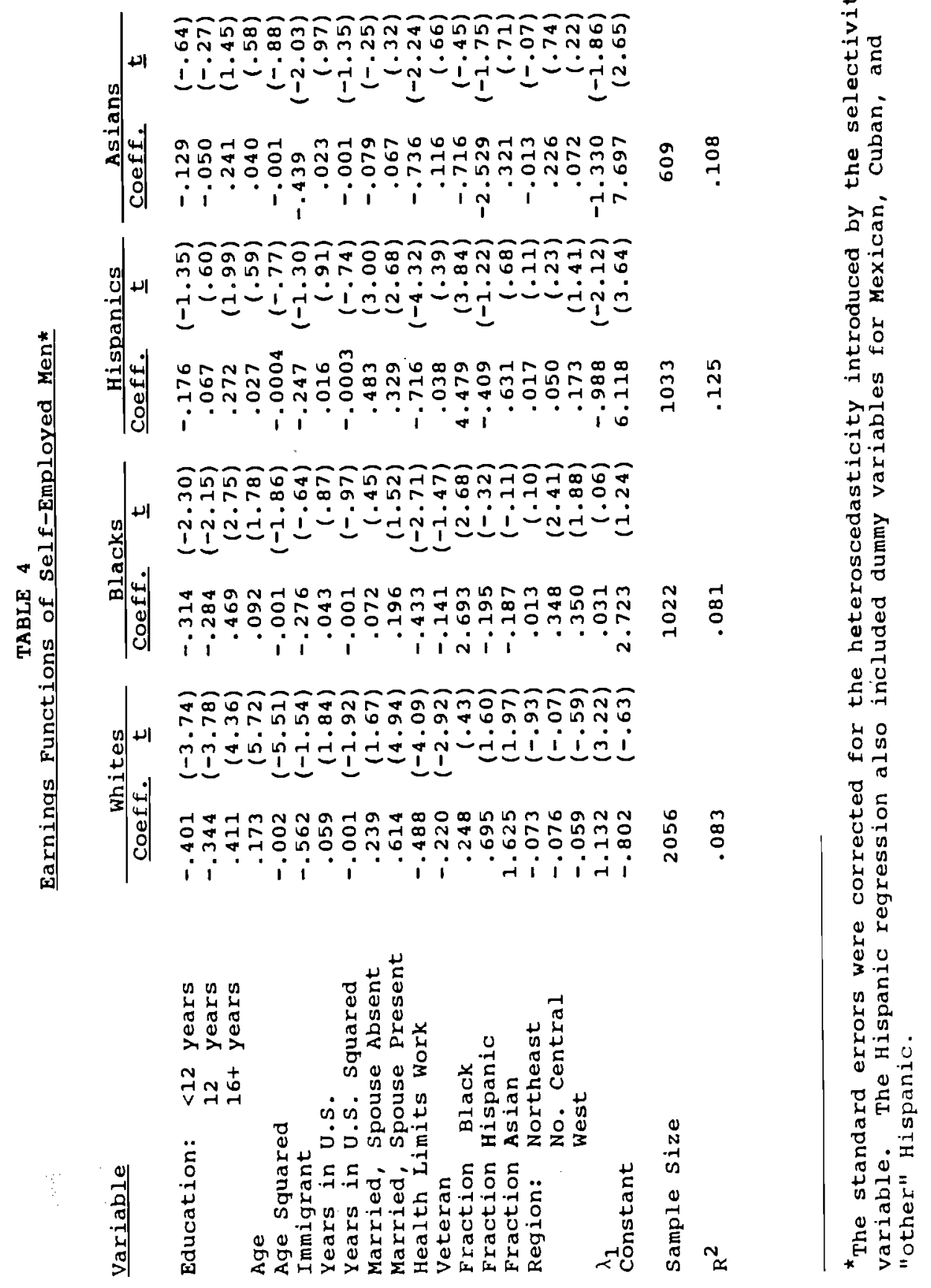




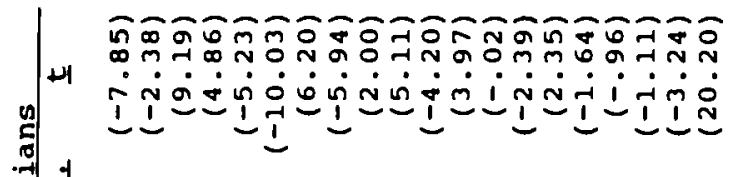

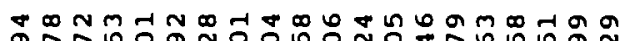

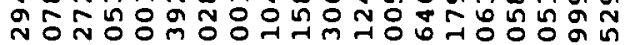

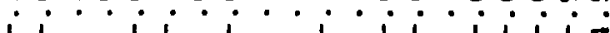

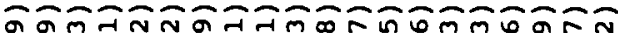

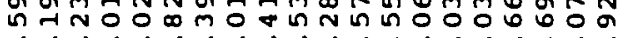
i $i$ i i i i i i i i i i i

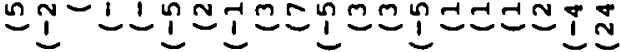

o a

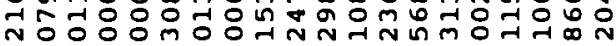
. . . . . . . . . . . . . . I

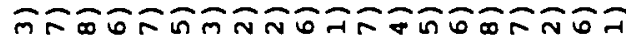

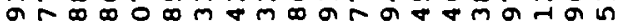
- . . . . . . . . . . . .

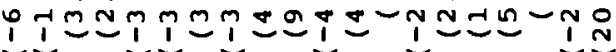

n

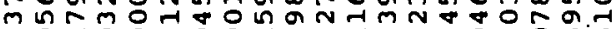

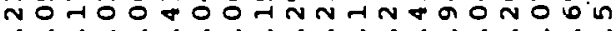

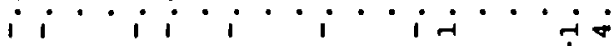

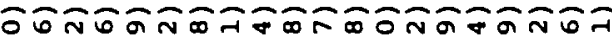
Or a a a n

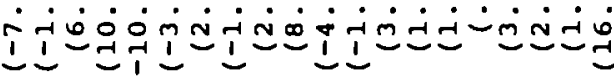

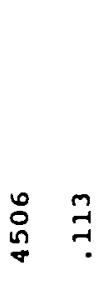

$>c$

ลั5

8.

0

굼

음

노

出

5 in

रे०

$\pm \frac{0}{0}$

0.-1

स.

$\rightarrow$

(

实

0

苋穷

망

ป 옹

ง

fin

म 0

는

ช

ڤ్

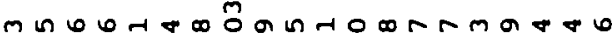

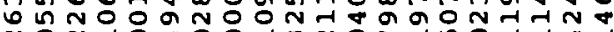

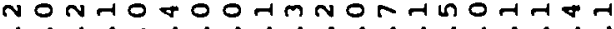
$i i \cdot i_{i} \cdot i i \cdots \cdot \cdots$

0 -

(1)

L

응

a)

(1)

का 0

$3 \cdot 5$

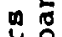

की

Lit 0

म 20

मू मू

$\coprod_{>}^{0} \stackrel{0}{>}$

ㄱํำ

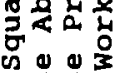




\section{TABLE 6}

Selectivity Coefficients by Occupation*

\begin{tabular}{|c|c|c|c|c|}
\hline \multirow[t]{2}{*}{ Group } & \multicolumn{2}{|c|}{ Professional } & \multicolumn{2}{|c|}{ Other } \\
\hline & Self-Emoloyed & Salaried & Self-Employed & Salaried \\
\hline Whites & $\begin{array}{r}.856 \\
(2.28)\end{array}$ & $\begin{array}{l}.156 \\
(.45)\end{array}$ & $\begin{array}{r}1.549 \\
(4.17)\end{array}$ & $\begin{array}{l}1.032 \\
(3.01)\end{array}$ \\
\hline Blacks & $\begin{array}{r}-.407 \\
(-.71)\end{array}$ & $\begin{array}{l}-1.886 \\
(-2.68)\end{array}$ & $\begin{array}{l}.202 \\
(.38)\end{array}$ & $\begin{array}{r}-1.440 \\
(-2.34)\end{array}$ \\
\hline Hispanics & $\begin{array}{r}-.699 \\
(-1.91)\end{array}$ & $\begin{array}{l}-2.148 \\
(-4.74)\end{array}$ & $\begin{array}{l}.218 \\
(.68)\end{array}$ & $\begin{array}{r}-.993 \\
(-3.01)\end{array}$ \\
\hline Asians & $\begin{array}{r}-1.356 \\
(-1.86)\end{array}$ & $\begin{array}{l}-1.347 \\
(-4.30)\end{array}$ & $\begin{array}{r}-1.014 \\
\quad(-1.37)\end{array}$ & $\begin{array}{r}-.331 \\
(-1.01)\end{array}$ \\
\hline
\end{tabular}

* The t-ratios are presented in parentheses. 
TABLE 7

Estimated Standard Deviations of (1n) Weekly Incomes

Group

Whites

BIacks

Hispanic

Asian

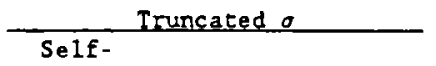

Employed Salaried Batio

1.27

.65

1.95

1.68

1. 52

1. 89

1. 31

.69

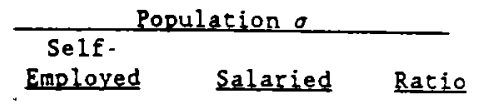

1.63

.69

2. 36

1. 35

1.07

1. 26

1.46

1. 15

1.27

1. 78

.88

2.03 
TABLE 8

Decomposition of Racial Wage Differentials

Self-Employment Sector Actual Wage Predicted Salaried Sector Differential Differential Between if Minority Whites and Minority Group Faced White Actual Wage Differential Predicted Groups Structure Between Differential Whites and Minority If Minority Group Faced White (are Groups Struc ture

$\begin{array}{lrrrr}\text { Blacks } & .469 & .194 & .385 & .116 \\ \text { Hispanics } & .276 & .048 & .394 & .176 \\ \text { Asians } & .053 & . .270 & .209 & .067\end{array}$

